\title{
Study on the Interaction between Rhodamine Dyes and Allura Red Based on Fluorescence Spectra and Its Analytical Application in Soft Drinks
}

\author{
Qianqian Sun, * Liu YANG, * Jidong YANG, ** Shaopu LIU,* and Xiaoli HU*广 \\ *Key Laboratory of Luminescent and Real-Time Analytical Chemistry (Southwest University), Ministry of \\ Education, College of Chemistry and Chemical Engineering, Southwest University, Chongqing 400715, China \\ **College of Chemical and Environmental Engineering, Chongqing Three Gorges University, Wanzhou, \\ Chongqing 404100, China
}

\begin{abstract}
Allura red (AR) is a common food additive. It is of significance to detect AR sensitively and selectively in soft drinks. In this report, fluorescence spectra of allura red-rhodamine dyes systems were studied. In a pH 6.0 Britton-Robinson buffer medium, the fluorescence of rhodamine dyes, such as rhodamine B (RB), butylrhodamine B (BRB) and rhodamine 6G (R6G), can be quenched by AR. Impressively, the emission spectrums of the RB and BRB change slightly upon the addition of AR, but it was clear that the emission of R6G decreased dramatically in the presence of AR. Thus, we have succeeded in planning an improved method for specifically detecting AR on the basis of hydrophobic forces and the electrostatic attraction between R6G and AR. The results show that AR could combine with R6G to form an ionassociation complex, which causes quenching of the emission intensity of R6G and changes of the UV-visible spectra. In this system, $0.097-6.0 \mu \mathrm{mol} \mathrm{L}-1$ AR could be simply detected owing to the decreased fluorescence of R6G in soft drinks, with a detection limit of $0.029 \mu \mathrm{mol} \mathrm{L}^{-1}$. In addition, we also optimized the reaction conditions and evaluated the effects of some coexisting substances. According to the fluorescence decay time, the UV-visible absorption spectra and the Stern-Volmer plots, the fluorescence quenching of R6G by AR is a static quenching process.
\end{abstract}

Keywords Allura red, rhodamine 6G, fluorescence quenching, soft drinks

(Received May 26, 2017; Accepted June 27, 2017; Published October 10, 2017)

\begin{abstract}
Although there are safety concerns, synthetic food color additives are commonly added to food and beverages to make products more appealing to consumers. ${ }^{1}$ It is thus vital to detect allura red sensitively and selectively. Allura red (AR, E129, see Fig. 1) is an artificial red azo dye, which is permitted for use in wine, ham, sausage, and jelly to improve the attraction of these foods and beverages. However, it can be bad on human health if consumed excessively. Potential health risks are caused by AR containing carcinogenic effects and genetic toxicity, ${ }^{2-4}$ but beyond that AR has potential behavioral influences on humans and animals, because remarkably increases hyperactivity in children. $^{5}$ In many countries, the uses of several food color additives, including AR, has been controlled or banned due to its toxicity. In China, the allowance of AR used in drinks is $0.1 \mathrm{~g} \mathrm{~kg}^{-1}$.

In recent years, much work has been done to develop various techniques, including voltammetry, ${ }^{7,8}$ differential pulse polarography, ${ }^{9-11}$ liquid chromatography or liquid chromatography/ mass spectrometry, ${ }^{12-17}$ spectrophotometry, ${ }^{18-22}$ capillary electrophoresis, ${ }^{23-25}$ to determine AR. Both voltammetry and differential pulse polarography can determine AR quickly and easily, but they are can not be applied to determine mixed food color additives in the food and beverages. Liquid chromatography or
\end{abstract}

$\dagger$ To whom correspondence should be addressed.

E-mail: xiaolihu@swu.edu.cn liquid chromatography/mass spectrometry methodologies have high separation efficiency, but the cost of analysis is high and the analyzer is huge and expensive. Regarding the spectrophotometry method, it is time-consuming because it needs a pretreatment before detection. As for the $\mathrm{CE}$, it is available due to their merits of easy operation, low consumption, and high efficiency, but its repeatability is not good. Thus, it is still a challenge to directly determine the concentration of AR in food and beverages. Therefore, it is pressingly needed to design an advanced and novel technique for detecting AR.

During the past few decades, a lot of analytical methods have been established on the basis of fluorescence quenching (on-off) between fluorophores and specific targets, and a new

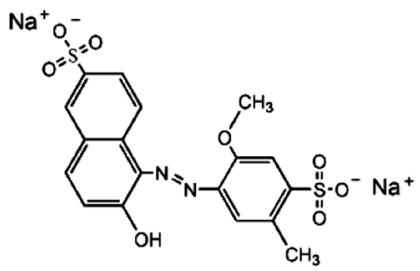

AR

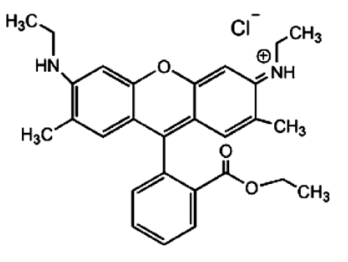

R6G
Fig. 1 The chemical structure of AR and R6G. 
avenue for sensitive, on-site, and selective determination of multifarious targets has been opened up by diverse quenching mechanisms. ${ }^{26}$ Ion-association complexes is a common phenomenon of fluorescence quenching results from the hydrophobic forces and the electrostatic attraction between two molecules with counter charge. Owing to great convenience, ion-association complexes has been widely used in optical sensing chemistry in recent years. For example, Zhang et al. employed acridine as a cationic alkaline fluorescence dye to sensitively detect sunset yellow based on ion-association complexes. ${ }^{27} \mathrm{Cui}^{28}$ and $\mathrm{Gan}^{29}$ et al. also devised analytical methods for detecting torasemide and carbazochrome on the basis of ion-association complexes. Recently, rhodamin dyes such as rhodamine B (RB), butylrhodamine B (BRB) and rhodamine $6 \mathrm{G}$ (R6G) have gained tremendous attention as cationic alkaline fluorescence dyes bacause of their advantages of strong fluorescence emission properties.

We discovered that in a Britton-Robinson buffer medium, the fluorescence of rhodamin dyes can be quenched by AR. The results show that the emission of the $\mathrm{RB}$ and $\mathrm{BRB}$ change slightly upon the addition of AR, but it was clear that the emission of R6G decreased dramatically in the presence of AR. Herein, we report on a new method for determing AR based on the fluorescence quenching of R6G (Fig. 1). According to what I know, no R6G as a fluorescence probe has been reported for the determination of AR. The sensor showed selectively signaling behavior towards AR and this approach supplies improved detection compared to the electrochemical techniques, polarography and voltammetry. Furthermore, a number of substances, including $\mathrm{MnSO}_{4}, \mathrm{NH}_{4} \mathrm{NO}_{3}, \mathrm{NaNO}_{2}$, and other amino acids would not effect the measurement.

\section{Experimental}

\section{Apparatus}

All fluorescence spectroscopic studies and UV-visible spectra were characterized by using an F-2500 spectroflurophotometer (Hitachi, Tokyo, Japan) and a UV-2450 spectrometer (Shimadzu, Japan), respectively. Fluorescence lifetimes of the AR-R6G systems were recorded using an FL-TCSPC Fluorolog-3 fluorescence lifetime system (Horiba Jobin Yvon Inc., France). A pHS-3D pH meter, (Shanghai Scientific Instruments Company, China) was employed for measuring $\mathrm{pH}$ values.

\section{Reagents}

The AR and RB, R6G and BRB stock solution were prepared at a concentration of $1.0 \times 10^{-3} \mathrm{~mol} \mathrm{~L}^{-1}$. Aqueous solutions were freshly prepared by diluting the corresponding stock solution. To prepare Britton-Robinson (BR) buffer solutions at different $\mathrm{pH}$ values, we used mixed acid (composed of $2.71 \mathrm{~mL}$ $85 \% \mathrm{H}_{3} \mathrm{PO}_{4}, 2.36 \mathrm{~mL} \mathrm{HAc}$ and $2.47 \mathrm{~g} \mathrm{H}_{3} \mathrm{BO}_{3}$ ) with $0.2 \mathrm{~mol} \mathrm{~L}^{-1}$ $\mathrm{NaOH}$. All chemicals used were of analytical grade.

\section{General procedure}

For fluorescence measurements, $1.5 \mathrm{~mL}$ RB, BRB solution $\left(1.0 \times 10^{-4} \mathrm{~mol} \mathrm{~L}^{-1}\right)$ containing different concentrations of AR ( 0 to $5.0 \times 10^{-6} \mathrm{~mol} \mathrm{~L}^{-1}$ ) at $\mathrm{pH} 6.0$ was added to a $10-\mathrm{mL}$ calibrated flask, and a 1.5-mL R6G solution $\left(1.0 \times 10^{-4} \mathrm{~mol} \mathrm{~L}^{-1}\right)$ containing different concentrations of $\mathrm{AR}\left(0\right.$ to $6.0 \times 10^{-6}$ mol L ${ }^{-1}$ ) at $\mathrm{pH} 6.0$ was added to a $10-\mathrm{mL}$ calibrated flask. Then, the mixture was made up to the mark with an appropriate amount of doubly distilled water and thoroughly mixed. Wait some minutes, fluorescence emission intensities of the reagent blank $\left(F_{0}\right)$ and the AR-RB, the AR-BRB, the AR-R6G system
$(F)$ were measured at room temperature $\left(20 \pm 5^{\circ} \mathrm{C}\right)$ with the slits set at 5.0/5.0 nm $\left(E_{\mathrm{x}} / E_{\mathrm{m}}\right)$.

\section{Results and Discussion}

\section{Fluorescence spectra}

The fluorescence emission spectra of RB, R6G and BRB are shown in Fig. 2. It can be observed from Fig. 2, in a pH 6.0 BR solution, the fluorescence spectra of RB (Fig. 2A), that BRB (Fig. 2B), R6G (Fig. 2C) had a maximum emission peak at $580,583,556 \mathrm{~nm}$ accordingly when excited at 556, 259, $274 \mathrm{~nm}$, respectively. With the increasing concentration of AR, the emission intensity $(F)$ of the RB and BRB changed slightly, yet a dramatic reduction of the emission intensity $(F)$ of R6G was observed. Furthermore, as we can see from the Figs. 2D - 2F, when the concentration of $\mathrm{RB}$ and $\mathrm{BRB}$ was $1.5 \mathrm{~mol} \mathrm{~L}^{-1}$, that corresponding fluorescence intensity is not strong enough for detection. They also has serious self-quenching; this phenomenon would interfere with the determination of AR. Thus, we can not make it clear that a slight change of the fluorescence intensity comes from the AR or self-quenching. Whereas, R6G has wonderful emission and its self-quenching can be neglected. From the above conclusions, we have succeeded in planning an improved method for specifically detecting $\mathrm{AR}$ on the basis of hydrophobic forces and the electrostatic attraction between R6G and AR. Notably, the maximum emission wavelength of $\mathrm{R} 6 \mathrm{G}$ had no clear changes, as was the fluorescence emission peak. In a certain range, $\Delta F$ $\left(F_{0}-F\right)$ of $\mathrm{R} 6 \mathrm{G}$ is proportional to the concentration of AR, so a novel method based on the fluorescence quenching of R6G can be used for detecting AR.

\section{Effect of the R6G concentration}

Firstly, we measured the emission intensity of R6G in the absence of AR. According to the tendency between the concentration of R6G and the fluorescence intensity, as observed from Fig. 3a, it is clear that the fluorescence emission intensity of R6G increased with increasing the concentration of R6G. As shown in the Fig. $3 b$, the intensity of this reaction system, however, was quenched, upon adding $\mathrm{AR}$ in this experiment. From the inset of Fig. 3, it can be found that the degree of fluorescence quenching reached the maximum and remained stable when the concentration of R6G was $0.75-2.0 \times$ $10^{-5} \mathrm{~mol} \mathrm{~L}^{-1}$. Therefore, $1.5 \times 10^{-5} \mathrm{~mol} \mathrm{~L}^{-1}$ was chose as a suitable concentration.

\section{The effects of acidity}

To explore the influence of the reaction media, the changes of the fluorescence intensity in rbinson buffer solution were carefully investigated. As shown in Fig. 4, it could be seen that both the fluorescence intensity of R6G (curve a) and the fluorescence intensity of AR-R6G (curve b) nearly remained stable with the change of the rbinson buffer solution. Moreover, from the inset of Fig. 4, the $\Delta F$ alsokept stable within 2.0 $10.0 \mathrm{pH}$ range. There is thus no denying that the acidity of the solution has slight influence on the AR-R6G system. Hence, $\mathrm{pH}$ 6.0 BR buffer solution was chose.

\section{Effects of the ionic strength}

The influence of the ionic strength on the AR-R6G reaction system was tested through changing the concentration of $\mathrm{NaCl}$ solution. As can be seen in Fig. 5, the $\Delta F$ changed mildly when the concentration of $\mathrm{NaCl}$ solution $<0.01 \mathrm{~mol} \mathrm{~L}^{-1}$. However, $\Delta F$ gradually decreased when the concentration of $\mathrm{NaCl}$ solution 

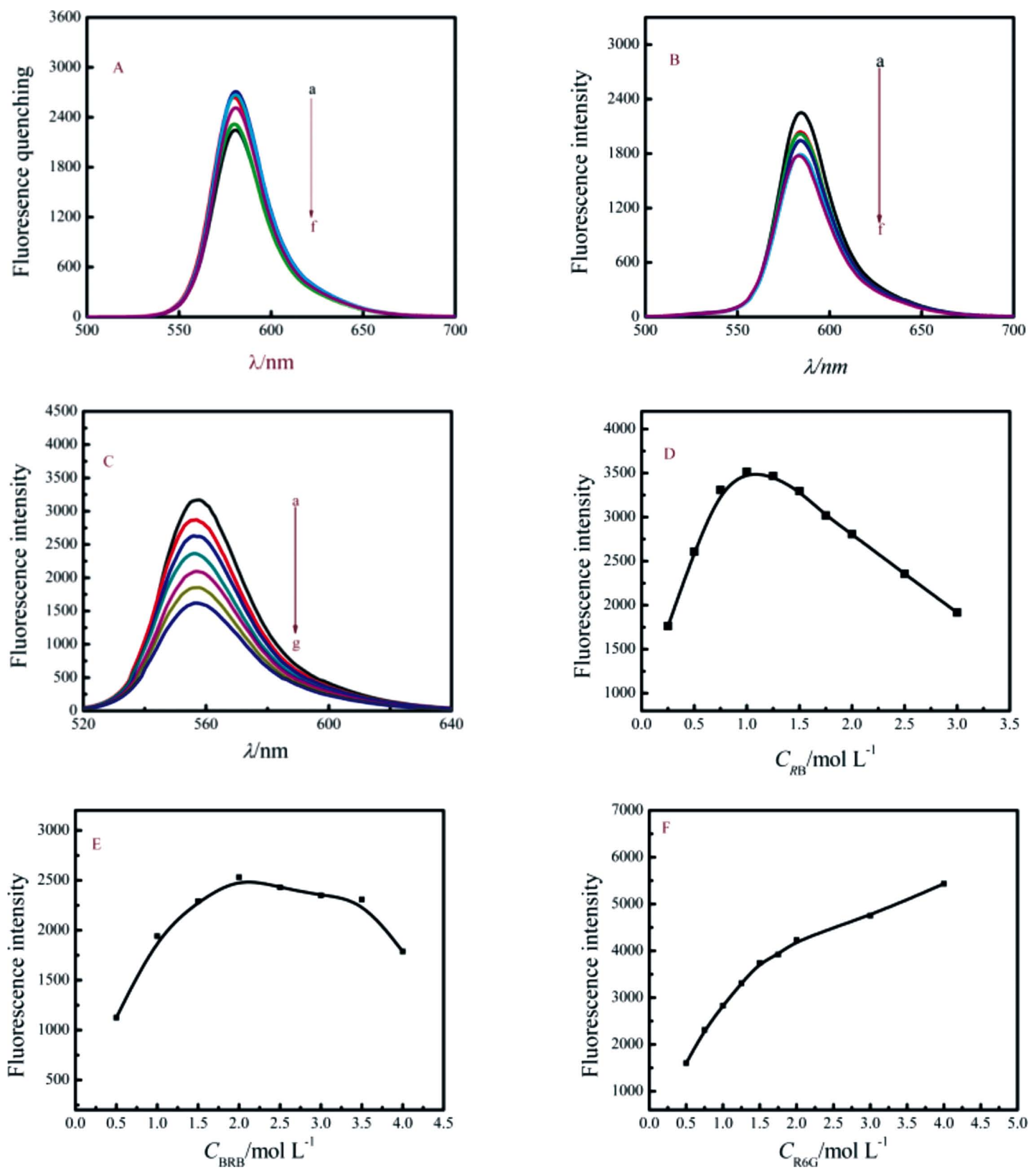

Fig. 2 Emission spectra of (A) a, RB; b - f, AR-RB system; AR, 0, 1.0, 2.0, 3.0, 4.0, $5.0 \mu \mathrm{mol} / \mathrm{L}$, respectively; RB, $1.5 \times 10^{-5} \mathrm{~mol} / \mathrm{L}$; $\mathrm{pH}$ 6.0. (B) a, BRB; b - f, AR-BRB system; AR, 0, 1.0, 2.0, 3.0, 4.0, $5.0 \mu \mathrm{mol} / \mathrm{L}$, respectively; BRB, $1.5 \times 10^{-5} \mathrm{~mol} / \mathrm{L} ; \mathrm{pH}$ 6.0. (C) a, R6G; b - g, AR-R6G system; AR, $0,1.0,2.0,3.0,4.0,5.0,6.0 \mu \mathrm{mol} / \mathrm{L}$, respectively; R6G, $1.5 \times 10^{-5} \mathrm{~mol} / \mathrm{L} ; \mathrm{pH} 6.0$. Effect of concentration on fluorescence intensity of RB/BRB/R6G. (D) RB, pH 6.0. (E) BRB, pH 6.0. (F) R6G, pH 6.0.

$>0.01 \mathrm{~mol} \mathrm{~L}^{-1}$. It is clear that the electrostatic interaction was a key factor in the AR-R6G reaction system, so this experiment should be done under a condition of low ionic strength.

\section{Selectivity of the method}

The effects of the common amino acids, metal ions, some similar food dyes and sugars on the detection of AR was investigated. As shown in Table 1, when the relative error was lower than $\pm 5 \%$, several common metal ions and sugars in drinks can be allowed with comparatively high concentration. Taking L-serine, methionine, arginine as examples, several times of certain common amino acids did not interfere with the determination. Besides what is mentioned above, most of the similar food dyes in the certain range did not interfere with the determination of AR with a relative error of less than 5\%. Whereas, Amaranth interfered. Fortunately, the amount of Amaranth in the drinks is extraordinary low and it could not affect the selectivity of this method. In a word, the method not only posed good selectivity, but also could be applied to detect AR.

\section{Calibration curve}

On the basis of the "General procedure", the fluorescence emission intensity of the AR-R6G system is measured. Calibration graph of $\Delta F$ towards the concentrations of $\mathrm{AR}$ is shown in Fig. 6. The graph was directly proportional to the concentration of $\mathrm{AR}$, with a correlation coefficient, $R^{2}=0.9992$. According to IUPAC recommendation, the quantitation limit $(10 \sigma / \mathrm{k})$ is $0.097 \mu \mathrm{mol} \mathrm{L}^{-1}$ and the detection limit $(3 \sigma / \mathrm{k})$ was 


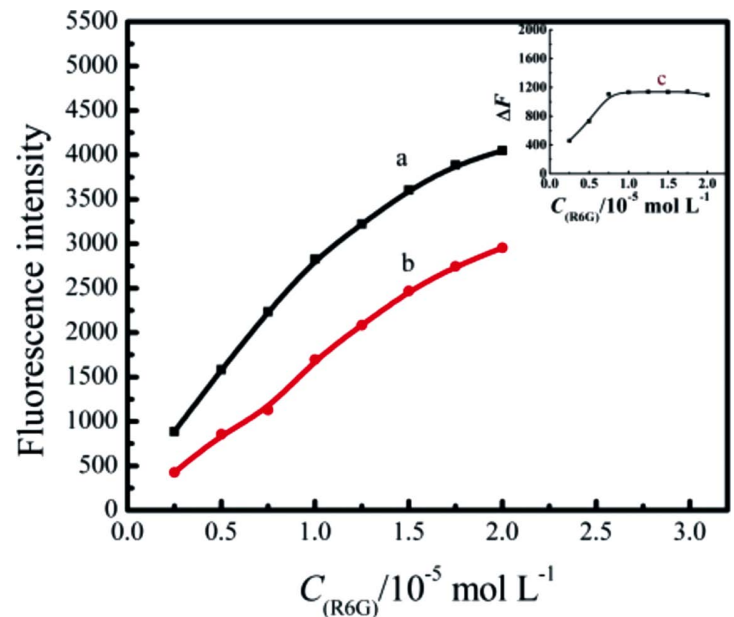

Fig. 3 Effect of the concentration of R6G. a, R6G; b, R6G-AR; c, $\Delta F=F_{0}-F ; C_{\mathrm{AR}}=4.0 \times 10^{-6} \mathrm{~mol} \mathrm{~L}^{-1} ; \mathrm{pH} 6.0 \mathrm{BR}$.

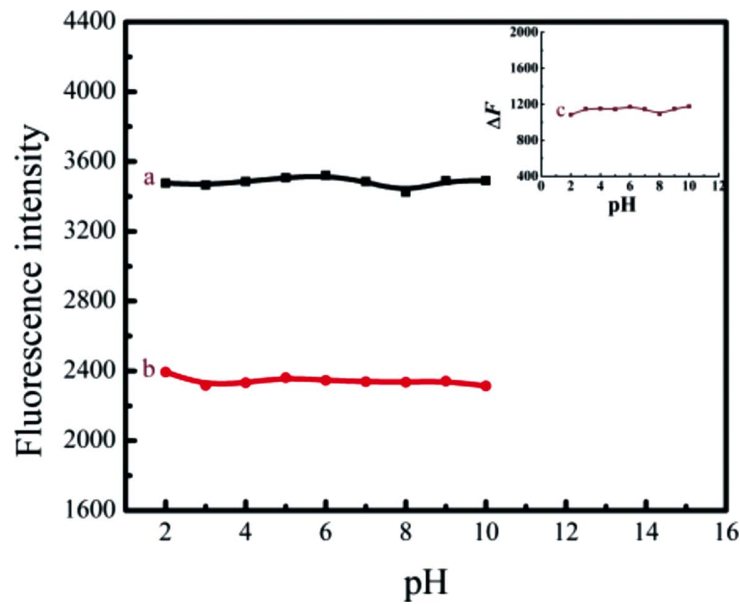

Fig. 4 Effect of pH. BR: a, R6G; b, R6G-AR; c, $\Delta F=F_{0}-F$; $C_{\mathrm{R} 6 \mathrm{G}}=1.5 \times 10^{-5} \mathrm{~mol} \mathrm{~L}^{-1} ; C_{\mathrm{AR}}=4.0 \times 10^{-6} \mathrm{~mol} \mathrm{~L}^{-1}$.

$0.029 \mu \mathrm{mol} \mathrm{L}^{-1}$, which was lower than lots of the recently reported methods (Table 2). The emission intensity of the ARR6G system was linearly proportional to AR in the concentration ranges of $0.097-6.0 \mu \mathrm{mol} \mathrm{L}-1$.

\section{Interaction of allura red with rhodamine $6 G$}

In aqueous solution, $\mathrm{AR}$ can exist as $\mathrm{AR}^{2-}$ and $\mathrm{AR}^{3-}$, and the distribution ratio depends on the solution acidity. ${ }^{6}$ On the basis of the dissociation constants of $\mathrm{AR}\left(\mathrm{p} K_{\mathrm{a}}=11.4\right),{ }^{30} \mathrm{AR}$ mostly existed as a bivalent anion due to the fact that hydroxyl of AR dissociate slightly in $\mathrm{pH} 6.0$ weak acid medium. As a cationic alkaline fluorescence dye, R6G existed as a univalent cation. Hence, in theory, 2 mol R6G can combine with $1 \mathrm{~mol} \mathrm{AR}$ to form an ion-association compound by hydrophobic forces and the electrostatic attraction. In order to exam the correctness of the theory, we determined the composition ratio of the complex by mole ratio method; the obtained results (Fig. 7) indicated that the ratio of $\mathrm{AR}$ and $\mathrm{R} 6 \mathrm{G}$ was 1:2. Furthermore, the interaction between AR and R6G is shown in Scheme 1.

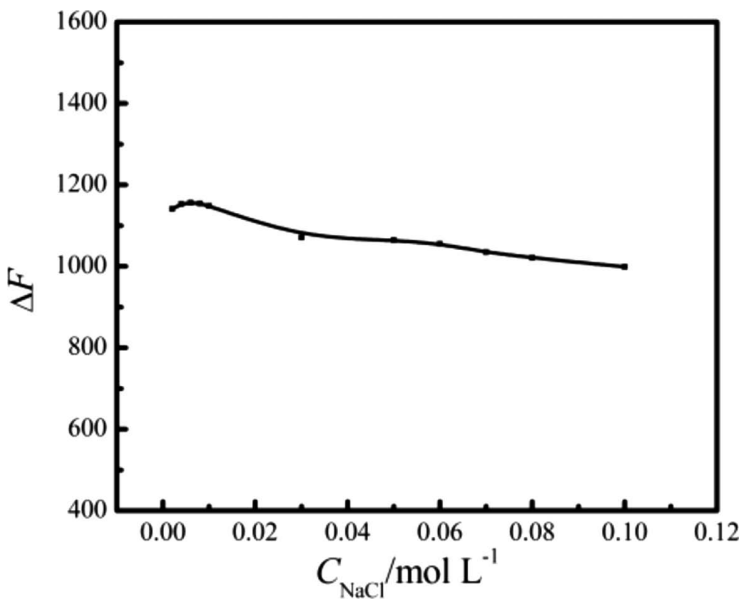

Fig. 5 Effects of the ionic strength. $C_{\mathrm{AR}}=4.0 \times 10^{-6} \mathrm{~mol} \mathrm{~L}^{-1} ; \mathrm{R} 6 \mathrm{G}=$ $1.5 \times 10^{-5} \mathrm{~mol} \mathrm{~L}^{-1} ; \mathrm{pH} 6.0 \mathrm{BR}$.

Table 1 Effects of coexisting substances $\left(C_{\mathrm{AR}}=4.0 \mu \mathrm{mol} \mathrm{L}^{-1}\right)$

\begin{tabular}{|c|c|c|c|c|c|}
\hline Species & $\begin{array}{l}\text { Concent- } \\
\text { ration/ } \\
\mu \mathrm{mol} \mathrm{L}-1\end{array}$ & $\begin{array}{c}\text { Relative } \\
\text { error, } \\
\%\end{array}$ & Species & $\begin{array}{l}\text { Concent- } \\
\text { ration/ } \\
\mu \mathrm{mol} \mathrm{L}\end{array}$ & $\begin{array}{c}\text { Relative } \\
\text { error, } \\
\%\end{array}$ \\
\hline $\mathrm{NiSO}_{4}$ & 300 & 0.9 & Ponceau 4R & 20 & 2.6 \\
\hline $\mathrm{KIO}_{3}$ & 300 & 2.1 & Sunset yellow & 25 & 3.6 \\
\hline $\mathrm{NaNO}_{2}$ & 300 & -0.4 & $\mathrm{CoSO}_{4}$ & 300 & -3.3 \\
\hline $\mathrm{NH}_{4} \mathrm{SCN}$ & 300 & -0.3 & $\mathrm{KBr}$ & 300 & 1.9 \\
\hline $\mathrm{NaF}$ & 300 & 0.4 & Glucose & 100 & 4.6 \\
\hline $\mathrm{Na}_{2} \mathrm{HPO}_{4}$ & 300 & -2.7 & L-Serine & 500 & -0.4 \\
\hline $\mathrm{MnSO}_{4}$ & 50 & -1.9 & Methionine & 100 & 2.3 \\
\hline $\mathrm{NH}_{4} \mathrm{NO}_{3}$ & 500 & 0.6 & Arginine & 500 & -2.0 \\
\hline $\mathrm{MgSO}_{4}$ & 100 & 3.4 & Sucrose & 500 & -0.9 \\
\hline Amaranth & 5 & 4.8 & Sodium citrate & 80 & 4.9 \\
\hline Methyl Orange & 25 & 3.2 & Isoleucine & 250 & 2.6 \\
\hline
\end{tabular}

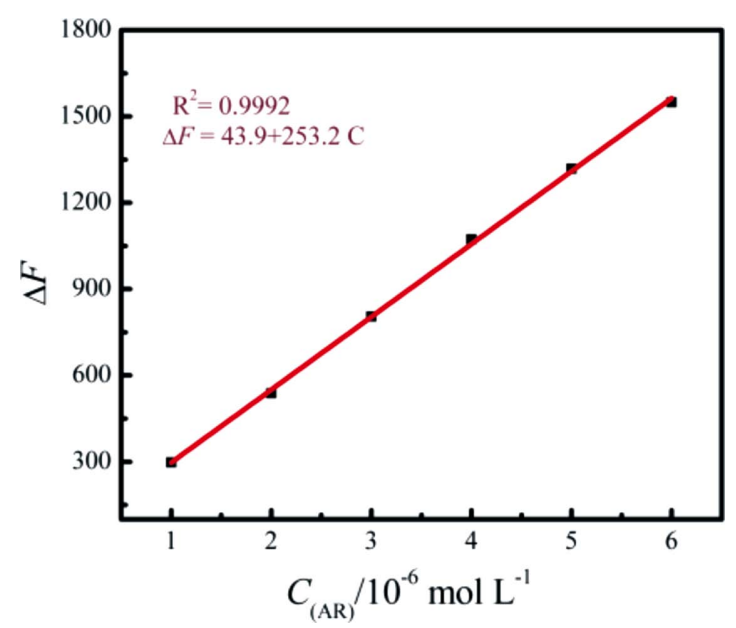

Fig. 6 Calibration graph of the AR-R6G system. $C_{\mathrm{R} 6 \mathrm{G}}=1.5 \times 10^{-5}$ $\mathrm{mol} \mathrm{L}{ }^{-1} ; C_{\mathrm{AR}}=1.0,2.0,3.0,4.0,5.0,6.0 \times 10^{-6} \mathrm{~mol} \mathrm{~L}^{-1} ; \mathrm{pH} 6.0$.

\section{Fluorescence quenching mechanism}

A process that reduces the emission intensity of a fluorescent probe is known as the quenching of fluorescence. Fluorescence quenching can be caused through all sorts of molecular 
Table 2 Analytical features of some typical methods employed for AR determination

\begin{tabular}{|c|c|c|c|c|}
\hline Method & $\begin{array}{l}\text { Linearity/ } \\
\mu \mathrm{mol} \mathrm{L}\end{array}$ & $\begin{array}{l}\text { Detection limit/ } \\
\quad \mu \mathrm{mol} \mathrm{L}-1\end{array}$ & Reagent & Remarks \\
\hline $\begin{array}{l}\text { Electrochemical } \\
\text { techniques }^{3}\end{array}$ & $0.10-1.21$ & 0.050 & $\begin{array}{l}\text { Alumina slurry, dihexadecyl } \\
\text { hydrogen phosphate }\end{array}$ & $\begin{array}{l}\text { Simple and selectivity, but mercury electrode is } \\
\text { toxic, bringing about environmental pollution }\end{array}$ \\
\hline Voltammetry $^{8}$ & $1.0-5.0$ & 0.30 & $\begin{array}{l}\text { Sb(III) solution, antimony } \\
\text { solution }\end{array}$ & $\begin{array}{l}\text { Not suitable for determining multiple food color } \\
\text { mixtures in the food matrix. }\end{array}$ \\
\hline Polarography ${ }^{9}$ & $0-9.06$ & 0.097 & $\begin{array}{l}\text { Potassium chloride, sodium } \\
\text { hydroxide, trisodium citrate }\end{array}$ & Simple and rapid method \\
\hline HPLC $^{12}$ & $0.046-102.7$ & 0.015 & $\begin{array}{l}\text { Ammonium acetate, sodium } \\
\text { hydroxide }\end{array}$ & $\begin{array}{l}\text { Possesses high separation efficiency, yet } \\
\text { equipments are expensive }\end{array}$ \\
\hline $\begin{array}{l}\text { Fluorescence } \\
\text { quenching method }\end{array}$ & $0.097-6.0$ & 0.029 & R6G & High sensitivity and accuracy, simple and rapid \\
\hline
\end{tabular}

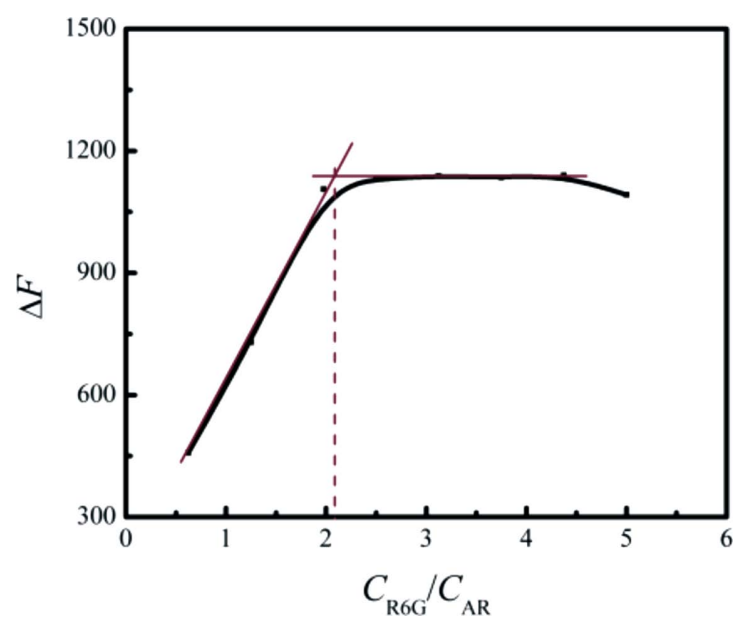

Fig. 7 The composition ratio of AR with R6G. $C_{\mathrm{AR}}=4.0 \mu \mathrm{mol} \mathrm{L}-1$; pH 6.0.

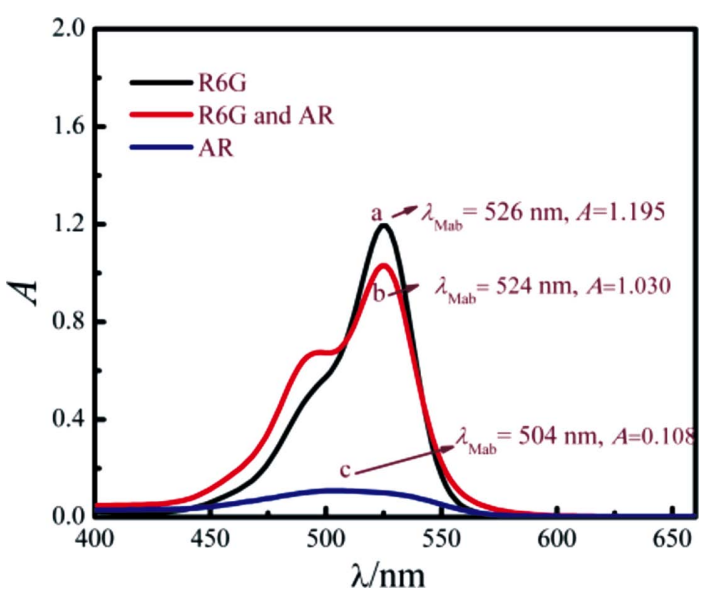

Fig. 8 Absorption spectra of a, AR; b, AR-R6G; c, R6G; d, curve $\mathrm{R} 6 \mathrm{G}+$ curve AR; $C_{\mathrm{R} 6 \mathrm{G}}=1.5 \times 10^{-5} \mathrm{~mol} \mathrm{~L}^{-1} ; C_{\mathrm{AR}}=4.0 \times 10^{-6} \mathrm{~mol} \mathrm{~L}^{-1}$; $\mathrm{pH} 6.0$.

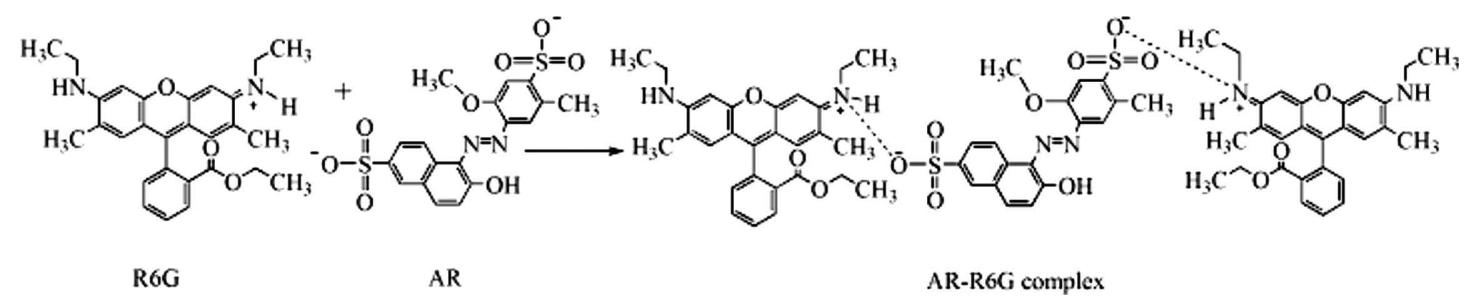

Scheme 1 Associated reaction between AR and R6G.

interactions, such as excited-state reactions, collisional reaction, ground-state complex formation and so on. In addition, the quenching mechanism, including dynamic quenching and static quenching. ${ }^{31}$ Firstly, the characteristics of the UV-visible absorption spectra of AR/R6G/AR-R6G were investigated to explore the quenching mechanism. As can be observed from Fig. 8, the absorption spectra of R6G (curve c), AR (curve a), and R6G-AR (complete reaction, curve b) system were obtained by using doubly distilled water as the blank. But beyond that, as shown, the curve $d$ is also obtained by adding the curve a with curve $c$. It is perfectly clear that the curve $b$ does not agree well with curve d, and the absorption peak of R6G at $526 \mathrm{~nm}$ decrease sharply when it interacted with AR, which not only proved that the quenching mechanism was static quenching, but also demonstrated that a new compound had formed. .,32 $^{6}$

To further understand the essence of the mechanism, the quenching constant was studied at different temperatures. As is known, the static quenching constant is reduced with the increasing temperature, whereas the dynamic quenching constant increases with the increase of temperature. ${ }^{33}$ In most instances, fluorescence quenching follows the Stern-Volmer (S-V) equation: ${ }^{34}$

$$
F_{0} / F=1+K_{\mathrm{q}} \tau_{0}[\mathrm{Q}]=1+K_{\mathrm{sv}}[\mathrm{Q}]
$$

Here $F_{0}$ and $F$ are the emission intensity in the absence and presence of quencher, accordingly; $\tau_{0}$ is the fluorescence emission lifetime in the absence of the quencher, and [Q] is the 


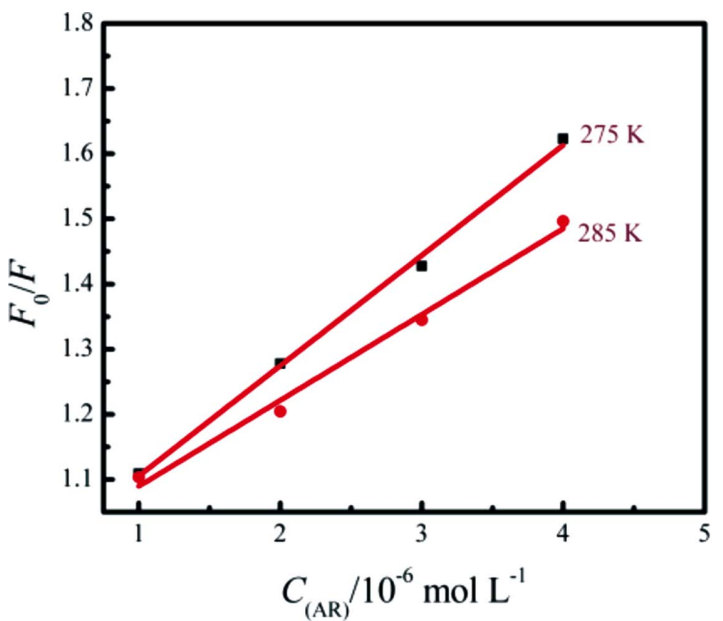

Fig. 9 Stern-Volmer plots for the solution systems at two differen temperatures in pH 6.0 BR. $C_{\mathrm{R} 6 \mathrm{G}}=1.5 \times 10^{-5} \mathrm{~mol} \mathrm{~L}^{-1}$.

concentration of quencher, $K_{\mathrm{q}}$ is the quenching constant and $K_{\mathrm{s} v}$ represent the $\mathrm{S}-\mathrm{V}$ quenching constant.

Figure 9 showed the S-V plots of $F_{0} / F$ against [Q] at two different temperatures, which depicts that the quenching constant is reduced with the increasing temperature. This implied that the quenching type of the AR-R6G system involved static quenching.

To strongly confirm the conclusion that the quenching type was static quenching, the fluorescence emission lifetime was measured. In theory, the fluorescence decay time $\left(\tau_{0}\right)$ of the fluorescence probe change little when static quenching happens Reversely, $\tau_{0}$ would be shorter if dynamic quenching occurs. That is, $\tau_{0} / \tau=F_{0} / F$ ( $\tau$ is fluorescence decay time of the fluorescence probe in the existence of quencher) for dynamic quenching; $\tau_{0} / \tau=1$ for static quenching. As can be seen from Fig. 10, the measured fluorescence decay time is 4.797 and $4.742 \mathrm{~ns}$ before and after the addition of AR. The fluorescence lifetime has a marginally small change, and $\tau_{0} / \tau \approx 1$, which suggested that the process is certainly a static quenching.

\section{Analytical application}

It is still a challenge for a planned fluorescent probe to analyze real samples due to potential unknown interferents. In order to investigate the applicability of the devised new method in real samples, the novel probe was used to test AR in soft drinks. The real sample came from a local store and used directly. In short, quantities of AR as added into drinks could be easily observed because the emission of R6G was immediately quenched. Furthermore, the prepared samples was analyzed by the standard addition method, and the results are shown in Table 3. The RSD was obtained through repeating the experiment 5 times under the same conditions. The RSD is below $5 \%$, suggesting that the results obtained by this proposed method are acceptable. In addition, the recoveries of AR in the drink samples range from 96.3 to $100.5 \%$, indicating that detection of AR using this novel method is accurate and feasible.

\section{Conclusions}

The interaction between AR, a common food additive, and rhodamine dyes had been investigated. In BR medium, the fluorescence of rhodamine dyes, such as RB, BRB and R6G can

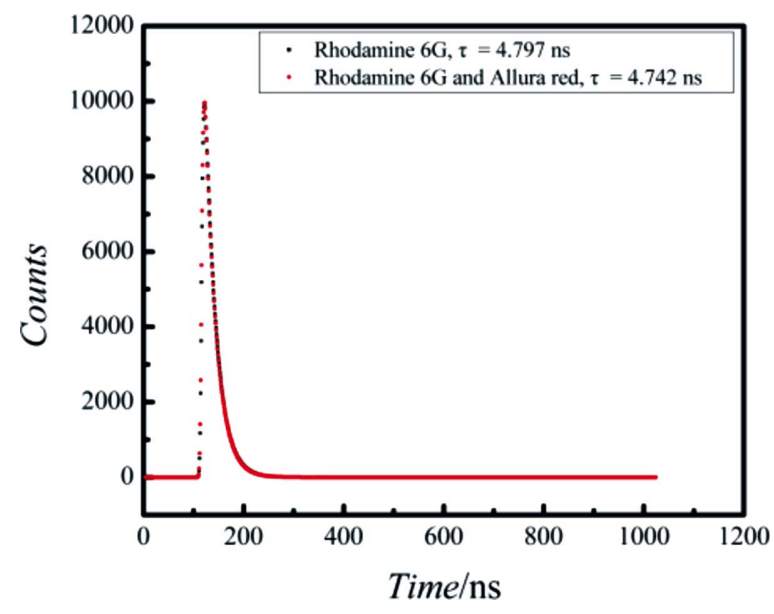

Fig. 10 Fluorescence emission decay curves of R6G and AR-R6G. $C_{\mathrm{R} 6 \mathrm{G}}=1.5 \times 10^{-5} \mathrm{~mol} \mathrm{~L}^{-1} ; C_{\mathrm{AR}}=4.0 \times 10^{-6} \mathrm{~mol} \mathrm{~L}^{-1} ; \mathrm{pH} 6.0$.

Table 3 Determination of AR in soft drinks

\begin{tabular}{|c|c|c|c|c|c|}
\hline Samples & $\begin{array}{c}\text { Found/ } \\
\mu \mathrm{mol} \mathrm{L}^{-1}\end{array}$ & $\begin{array}{c}\text { Added/ } \\
\mu \mathrm{mol} \mathrm{L}-1\end{array}$ & $\begin{array}{l}\text { Total found } \\
\quad(n=5)\end{array}$ & $\begin{array}{c}\text { Recovery, } \\
\%\end{array}$ & $\begin{array}{c}\mathrm{RSD}, \% \\
(n=5)\end{array}$ \\
\hline 1 & 1.74 & 2.0 & $\begin{array}{l}3.89,3.85,3.85 \\
3.58,3.53\end{array}$ & 99.6 & 4.6 \\
\hline 2 & 1.79 & 4.0 & $\begin{array}{l}5.90,5.84,5.78 \\
5.77,5.75\end{array}$ & 100.5 & 1.1 \\
\hline 3 & 1.75 & 6.0 & $\begin{array}{l}7.64,7.50,7.51 \\
7.50,7.48\end{array}$ & 96.3 & 0.9 \\
\hline
\end{tabular}

be quenched by AR. Notably, the emission spectrums of the RB and $\mathrm{BRB}$ change little in the presence of AR, but it was clear that the emission of R6G decreased dramatically in the presence of AR. Thus, the one novel, easy and fast method for the recognition of $\mathrm{AR}$ was planned on the basis of hydrophobic forces and the electrostatic attraction between R6G and AR. The results show that AR could combine with R6G to form an ion-association compound, which causes quenching of the emission intensity of R6G and changes of the UV-visible spectra. In this system, the graph was directly proportional to the concentrations of AR and $0.097-6.0 \mu \mathrm{mol} \mathrm{L}^{-1} \mathrm{AR}$ could be simply detected owing to the decreased fluorescence of R6G in soft drinks, with a detection limit of $0.029 \mu \mathrm{mol} \mathrm{L}^{-1}$. According to the fluorescence decay time, the UV-visible absorption spectra and the Stern-Volmer plots, the fluorescence quenching of R6G by AR is a static quenching process.

\section{Acknowledgements}

The authors gratefully acknowledge financial support for this study by grants of the National Natural Science Foundation of China (Grant No. 21475014), the Special Fund of Chongqing Key Laboratory (CSTC) and the Fundamental Research Funds for the Central Universities (XDJK2013A022).

\section{References}

1. M. Tripathi, S. K. Khann, and M. Das, Food Control., 2007, 
$18,211$.

2. N. Pourreza, S. Rastegarzadeh, and A. Larki, Food Chem., 2011, 126, 1465.

3. Y. Zhang, X. J. Zhang, X. H. Lu, J. Q. Yang, and K. B. Wu, Food Chem., 2010, 122, 909.

4. F. Gosetti, U. Chiuminatto, E. Mazzucco, G. Calabrese, M. C. Gennaro, and E. Marengo, Food Chem., 2013, 136, 617.

5. D. McCann, A. Barrett, A. Cooper, D. Crumpler, L. Dalen, K. Grimshaw, E. Kitchin, K. Lok, L. Porteous, E. Prince, E. Sonuga-Barke, J. O. Warner, and J. Stevenson, Lancet, 2007, 370, 1560.

6. Y. Shi, C. Li, S. P. Liu, Z. F. Liu, J. D. Yang, J. H. Zhu, M. Qiao, R. L. Duan, and X. L. Hu, RSC Adv., 2014, 4, 37100.

7. M. L. S. Silva, M. B. Q. Garcia, J. L. F. C. Lima, and E. Barrado, Talanta, 2007, 72, 282.

8. J. A. Rodríguez, M. G. Juárez, C. A. Galán-Vidal, J. M. Miranda, and E. Barrado, Electroanalysis, 2015, 27, 2329.

9. S. Combeau, M. Chatelut, and O. Vittori, Talanta, 2002, 56, 115.

10. S. Chanlon, L. Joly-Pottuz, M. Chatelut, O. Vittori, and J. L. Cretier, J. Food Compos. Anal., 2005, 18, 503.

11. P. L. López-de-Alba, L. López-Martínez, and L. M. DeLeón-Rodríguez, Electroanalysis, 2002, 14, 3.

12. K. S. Minioti, C. F. Sakellariou, and N. S. Thomaidis, Anal. Chim. Acta, 2007, 583, 103.

13. F. Gosetti, U. Chiuminatto, E. Mazzucco, G. Calabrese, M. C. Gennaro, and E. Marengo, Anal. Chim. Acta, 2012, 746, 84.

14. X. H. Chen, Y. G. Zhao, H. Y. Shen, L. X. Zhou, S. D. Pan, and M. C. Jin, J. Chromatogr. A, 2014, 1346, 123.

15. T. T. Zou, P. L. He, A. Yasen, and Z. Li, Food Chem., 2013, $138,1742$.

16. N. Yoshioka and K. Ichihashi, Talanta, 2008, 74, 1408.

17. S. Bonan, G. Fedrizzi, S. Menotta, and C. Elisabetta, Dyes Pigm., 2013, 99, 36.
18. P. L. López-de-Alba, K. Wróbel-Kaczmarczyk, K. Wróbel, L. López-Martínez, and J. A. Hernández, Anal. Chim. Acta, 1996, 330, 19.

19. E. Dinc, E. Baydan, M. Kanbur, and F. Onur, Talanta, 2002, 58,579 .

20. E. Heidarizadi and R. Tabaraki, Talanta, 2016, 148, 237.

21. M. Soylak, Y. E. Unsal, and M. Tuzen, Food Chem. Toxicol., 2011, 49, 1183.

22. J. J. Berzas-Nevado, C. Guiberteau-Cabanillas, A. M Contento-Salcedo, and R. Martín-Villamuelas, Anal. Lett. 1999, 32, 1879.

23. H. Y. Huang, Y. C. Shih, and Y. C. Chen, J. Chromatogr. A, 2002, 959, 317.

24. M. A. Prado, L. F. Vilas Boas, M. R. Bronze, and H. T. Godoy, J. Chromatogr. A, 2006, 1136, 231.

25. M. C. Boyce, Electrophoresis, 2001, 22, 1447.

26. M. Lin, H. Y. Zou, T. Yang, Z. X. Liu, H. Liu, and C. Z. Huang, Nanoscale, 2016, 8, 2999.

27. H. Zhang, X. Zhao, S. Liu, J. Yang, R. Duan, Y. Yuan, and X. Hu, Anal. Sci., 2017, 33, 243.

28. Z. P. Cui, S. P. Liu, Z. F. Liu, Y. F. Li, X. L. Hu, and J. Tian, Spectrochim. Acta, Part A, 2013, 114, 547.

29. X. J. Gan, S. P. Liu, Z. F. Liu, X. L. Hu, Z. P. Cui, and Y. Q. Wang, Spectrochim. Acta, Part A, 2012, 97, 161.

30. M. Pérez-Urquiza and J. L. Beltrán, J. Chromatogr. A, 2001, 917, 331.

31. J. Wang, H. B. Liu, S. Y. Park, S. Y. Kim, T. Joo, and C. S. Ha, RSC Adv., 2012, 2, 4242.

32. Y. S. Yuan, X. Huang, S. P. Liu, J. D. Yang, R. L. Duan, and X. L. Hu. RSC Adv., 2016, 6, 3393.

33. X. L. Li, Y. J. Hu, H. Wang, B. Q. Yu, and H. L. Yue, Biomacromolecules, 2012, 13, 873.

34. B. G. Evale and S. M. Hanagodimath, J. Lumin., 2010, 130, 1330. 